\title{
Design and Analysis of Welding Fixture for Elementary Weld Joints
}

\author{
Neeraj Kumar Jha ${ }^{1}$ and Raghu Prem B ${ }^{2}$ \\ ${ }^{1}$ Assoc. Professor, CVR College of Engineering/ Mechanical Department, Hyderabad, India \\ Email: neerajjha.me@gmail.com \\ ${ }^{2}$ Senior Engineer, Voltas Limited/ Mumbai, India \\ Email: premraghu63@gmail.com
}

\begin{abstract}
Fixtures are tools and contributes to increasing manufacturing efficiency and productivity. They are utilized in various manufacturing processes to rest, support and locate the workpiece. Welding fixtures are utilized in fabrication shops. They are specifically utilized to hold and locate the metallic plates and piece parts for permanent joining. They appear simple in construction but to develop an effective welding fixture, deep knowledge of design and manufacturing is required. Welding fixtures can be under static load from the workpiece they are supporting as well as under thermal stresses due to heat liberated by the particular welding process. The purpose of this paper is to provide a model and analyze a compact welding fixture and to illustrate few weld joints for small metal plates. The same model can be utilized efficiently to weld metal plates with variations in dimensions within some range. Software used for modeling of parts is CATIA V5R20 and that for the analysis is ANSYS 16.0
\end{abstract}

Index Terms: Fixture, Welding, Manufacturing efficiency, Productivity, Static load, Thermal stress, Weld joints, CATIA V5R20, ANSYS 16.0

\section{INTRODUCTION}

Welding is process of joining metal parts in the presence of heat. Pressure is also applied in some processes of welding. Melting point, thermal conductivity, electric resistance and surface condition of the metal to be joined are those factors which must be studied well before designing a welded joint [1]. A lot of controlled parameters contribute to a defect free weld joint. Otherwise defects are unavoidable either in weldment or in welded joints. The correct welding technique is another important aspect to be taken care of while obtaining a weld joint. Defects like excess fusion, lap, undercut, improper fusions etc. are outcomes of a poor welding technique. Other defects like distortion or warpage is also observed in a welded joint which is a combined contribution of poor welding techniques and behavior of metal against thermal expansion and contraction. Once a weld joint is designed, it is the task of the welder to accomplish the joint, based on his skill with the available equipments. Proper work alignment is additional task which is to be taken care by a welder. With improper workholding and misaligned piece parts, a proper weld joints cannot be obtained.

To overcome the problems occurring in welded parts due to improper workholding, especially designed tools called welding fixtures are introduced in fabrication industries. A welding fixture is used to have proper provision of locating the piece parts and holding them firmly, so that these parts can be joined permanently by a suitable welding process. A welding fixture is a special purpose tool which is used to obtain one type of weld part usually. These fixtures are used at various stages in a fabrication shop to join various shapes, sizes and types of metals. Use of welding fixtures eases job setting work of a welder. These are economically used in mass production and especially when to be joined part profile is very complex. Based on the part geometry and design of welded joint, design of welding fixture can also be complicated to complex.

In the past there was limited research and applications in the welding sector. But, due to importance of welding for sheet metal in automobile and aerospace industries, the importance of welding has received special attention from designers, manufacturers and researchers. A weld fixture is often developed to reduce the deformation of each workpiece due to heat and residual stress in the welding process to reduce the dimensional variation of the assembly. Thus deformation analysis must be done to enhance the ability of the fixture on deformation controlling [2, 3$]$.

While designing a welding fixture the following points must be considered [4]:

1. Expansion of heated workpiece and resultant distortion should not affect proper location, clamping, loading unloading and melting. Thus adequate clearance must be provided between workpiece and locators.

2. Welding spatters should not be allowed to fall on the threaded parts of the clamping elements. Thus the toggle clamps without threaded parts should be used in welding fixtures.

3. Provision for spatter grooves should be there below the line of welding.

4. Care should be taken to check that the joined workpiece does not get stuck or locked in the welding fixture.

5. For workpiece which need welding from a number of sides, a provision for easy tilting or rotating the fixture should be made, to simplify welding from various sides.

Based on above mentioned design considerations, this paper aims at designing and analyzing a compact welding fixture which can be used suitably to prepare Lap, Butt and T-weld joints on mild steel plates within the dimension range of $50 \times 50 \times 5 \mathrm{~mm}$ to $50 \times 100 \times 20 \mathrm{~mm}$. 


\section{JOINT DESIGN}

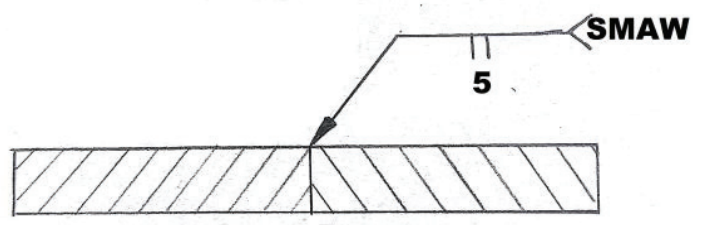

Figure 1. Butt Joint Design

Figure 1 indicates joint design for square butt weld for butt joint. Figure 2 indicates joint design for fillet weld for lap joint. T- Joint to be obtained by fillet weld is indicated in Figure 3. Size of weld is $5 \mathrm{~mm}$ and considered plate size for the joint is $50 \mathrm{X} 100 \mathrm{X} 5 \mathrm{~mm}$. Shielded metal arc welding (SMAW) is considered as welding process for further design considerations and analysis.

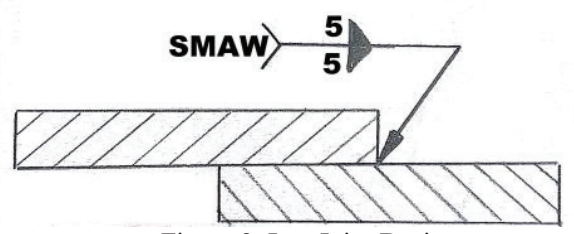

Figure 2. Lap Joint Design

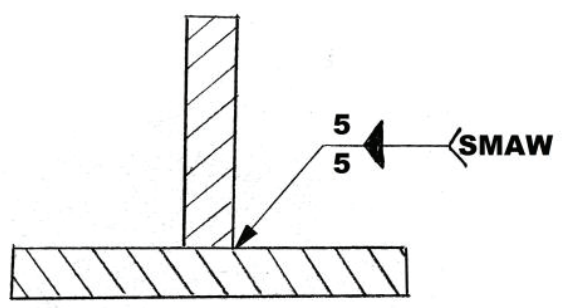

Figure 3. T- joint Design

Table I represents few process variables related to SMAW process [5]. Current setting, polarity, electrode diameter and flux composition are among a few parameters which must be set properly to obtain a good quality weldment with good appearance by SMAW process. Otherwise weldment with non-uniform temperature and excess of spatters can be observed. These factors lead to defected, weak weld joints which are poor in appearance.

TABLE I.

PROCESS PARAMETERS RELATED TO SWAW

\begin{tabular}{|l|l|}
\hline \multicolumn{2}{|c|}{ PROCESS PARAMETERS RELATED TO SWAW } \\
\hline Electrode Type & Electric Arc \\
\hline Operating Current & Consumable \\
\hline Operating Voltage & $30-300 \mathrm{~A}$ \\
\hline Max. Temperature & $15-45 \mathrm{~V}$ \\
\hline Optimum Welding Speed & $5000^{\circ} \mathrm{C}$ \\
\hline Position Of Weld & $75-150 \mathrm{~mm} / \mathrm{min}$ \\
\hline Mode Of Operation & All \\
\hline Weld Quality & Manual \\
\hline
\end{tabular}

As the plates to be joined are considered $5 \mathrm{~mm}$ thick and SMAW gives deposition at high temperature, without beveling of the edges sufficient depth of penetration can be ensured for butt weld joint. But for good depth of penetration, the surfaces are assumed clean and free from any layer of scale, rust and lubricant.

Material selection is an inseparable part of the design. For analysis it is another important aspect to consider in design phase. Mild Steel (MS) is selected for the purpose of fixture design due to its own advantages. Mild steel is a ductile metal at room temperature. It has adequate strength against loads as well as it is not costly. Thus for moderate strength mild steel can be easily used. Few of the important characteristics of mild steel are enlisted in Table II [5].

TABLE II.

MATERIAL SPECIFICATION MiLD STEEL (MS)

\begin{tabular}{|l|l|}
\hline Density & $7800-7900 \mathrm{~kg} / \mathrm{m}^{3}$ \\
\hline Melting Point & $1370{ }^{\circ} \mathrm{C}$ \\
\hline Carbon Content & $0.08-0.25 \% \mathrm{wt}$ \\
\hline Elasticity Modulus & $2.1 \times 10^{5} \mathrm{MPa}$ \\
\hline Elongation & $26-47 \%$ \\
\hline Yield Strength & $250-395 \mathrm{MPa}$ \\
\hline Tensile Strength Thermal & $345-580 \mathrm{MPa}$ \\
\hline $\begin{array}{l}\text { Coefficient of } 10^{6} /{ }^{\circ} \mathrm{C} \\
\text { Expansion }\end{array}$ \\
\hline
\end{tabular}

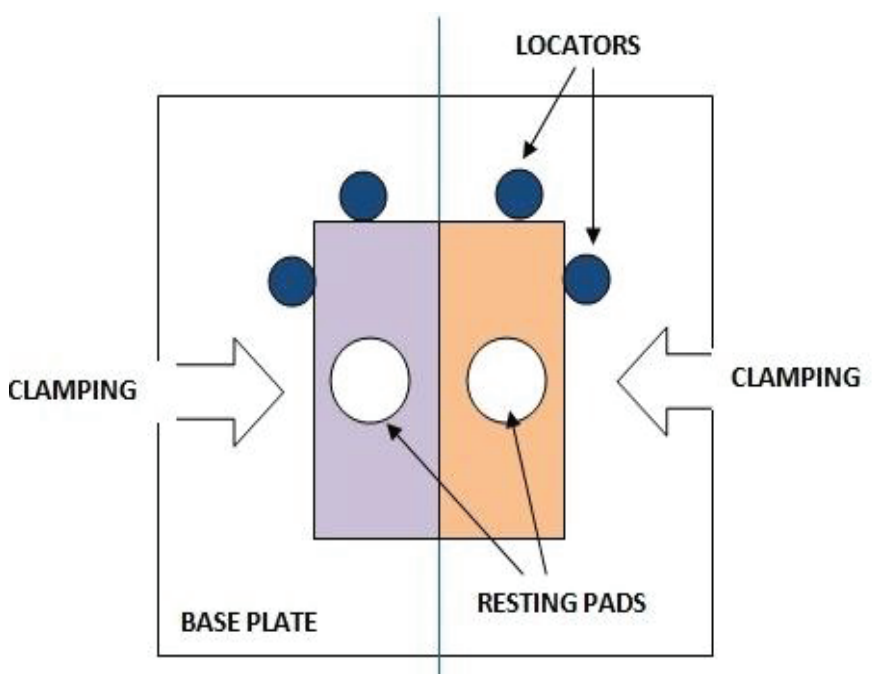

Figure 4. Base Plate Size Estimation

\section{Design ESTimations AND FIXTURE DESIGN}

Based on design considerations and the to be welded plate size, base plate dimension is estimated as $254 \mathrm{X} 254 \mathrm{~mm}$ and the same is shown in Figure 4. Estimation of plate size is important because not only it has to rest and locate the weld plates but the same plate has to accommodate the clamping devices also.

There are three main structural components in a fixture viz. locator, clamp and support. Locator is a stationary part unlike clamp which is movable. The locator can be a pin or a surface. Clamps are specifically designed mechanisms to apply force to grip the workpiece. Support is mostly stable on fixture, it holds the work piece and it helps the work 
piece in keeping its geometry under thermal stresses. Thermal stresses rises because of heat output of welding process. [6].

Overall dimension estimated for base plate is $254 \mathrm{X}$ $254 \mathrm{~mm}$ and it can accommodate upto $150 \mathrm{~mm}$ long MS plates for welding. Figure 4 further indicates feasible positions of resting and location. Locators are required in all manufacturing processes as their work is to overcome complex alignment of the workpiece [7].

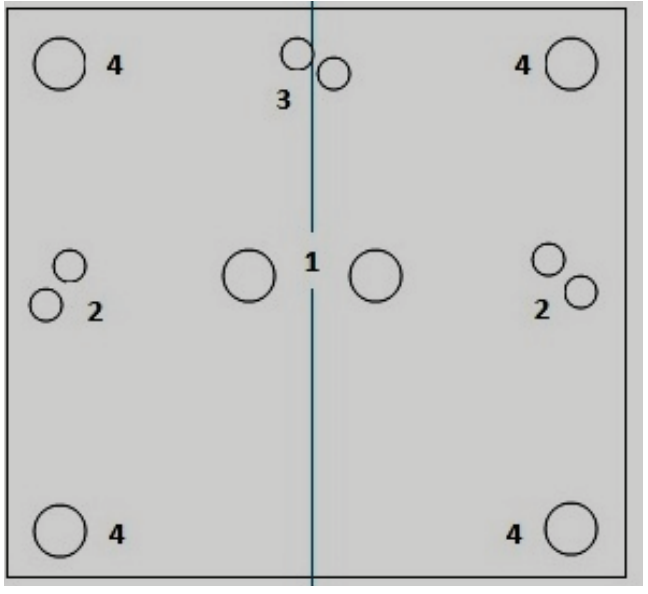

Figure 5. Reference Positions in Base Plate

In Figure 5, hole positions represented by 1 indicates position of rest pads to support weld plates in lap and butt arrangement. Holes indicated by 2 are for clamping devices.

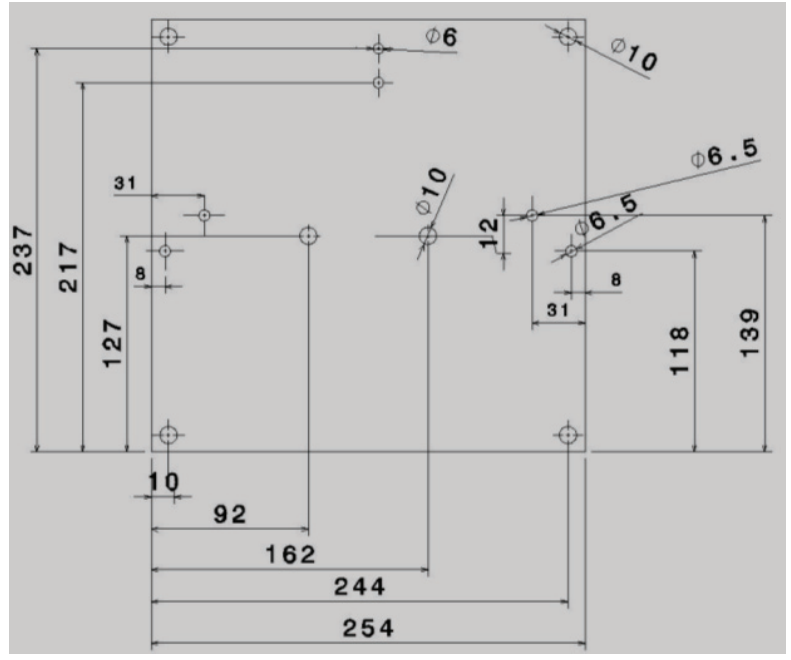

Figure 6. Base Plate Drafting (all dimensions are in $\mathrm{mm}$ )

Position 3 indicates place for bracket which is special attachment for T- joint. Positions indicated by 4 are support for base plate. Dimensional representation for base plate is in Figure 6.

Flat machined rest pads are implemented for resting of weld plates. They are adjustable in nature. When these pads have to rest weld plates for butt joint, they will be in contact with the surface of the base plate. Weld plates at this position will be facing each other. Same position can be utilized if there is requirement of groove weld on plates of various thicknesses. There is ample gap between rest pads to dissipate heat liberated by welding as well as for collection of spatters.

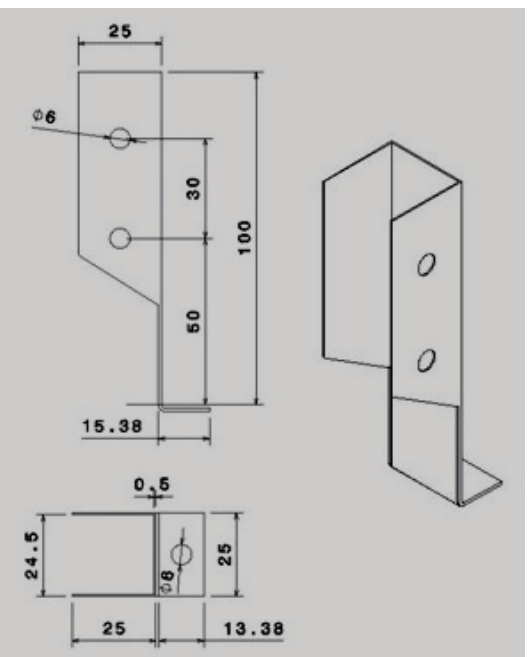

Figure 7. T-joint Bracket Drafting (all dimensions are in $\mathrm{mm}$ )

When there is a requirement of lap joint, one rest pad will be lifted to plate thickness height so that the plates can overlap.

For T-joint, a formed bracket is installed at one end of base plate. It is planned and designed such that it can support vertical plate upto $20 \mathrm{~mm}$ thickness over $40 \mathrm{~mm}$ thick plate in T position. This bracket is shown in Figure 7.

Bases on design consideration, lift type toggle clamps are used for holding weld plates. Freedom of adjustments are achieved with bolts and wing nuts of various dimensions. Assembled welding fixture model is shown in Figure 8.

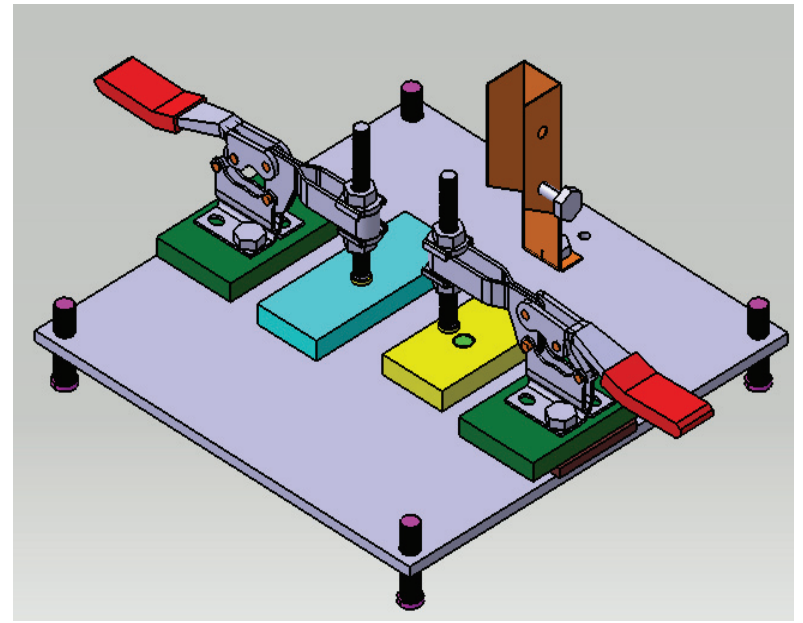

Figure 8. Designed Welding Fixture Model

Part description of the designed fixture is shown in Table III. Proper view of assembly to indicate all of its parts is represented in Figure 9. 
TABLE III.

BILL OF MATERIAL

WELDING FIXTURE

\begin{tabular}{|c|l|c|c|c|}
\hline S.No. & $\begin{array}{c}\text { Component } \\
\text { Name }\end{array}$ & Material & Dimension & Qty. \\
\hline 1 & Base Plate & MS & $254 \times 254 \times 6 \mathrm{~mm}$ & 1 \\
\hline 2 & Toggle Clamps & Standard & $\begin{array}{c}\text { Clamping Force } \\
\text { upto } 25 \mathrm{~N}\end{array}$ & 2 \\
\hline 3 & Nuts and Bolts & MS & M6 & 5 \\
\hline 4 & Nuts and Bolts & MS & M10 & 6 \\
\hline 5 & Clamps Support & MS & $80 \times 50 \times 10 \mathrm{~mm}$ & 2 \\
\hline 6 & T- joint bracket & MS & $25 \times 25 \times 115 \mathrm{~mm}$ & 1 \\
\hline 7 & Rest Pad -1 & MS & $70 \times 40 \times 11 \mathrm{~mm}$ & 1 \\
\hline 8 & Rest Pad -2 & MS & $100 \times 40 \times 11 \mathrm{~mm}$ & 1 \\
\hline 9 & Wingnut & MS & M6 & 1 \\
\hline 10 & Wingnut & MS & M10 & 2 \\
\hline
\end{tabular}

Numbers of parts used in welding fixture are kept low. Less number of parts ensures lesser maintenance requirement for fixture as well as less overall weight of the fixture. Indirectly, compactness of the model is ensured by less number of parts.

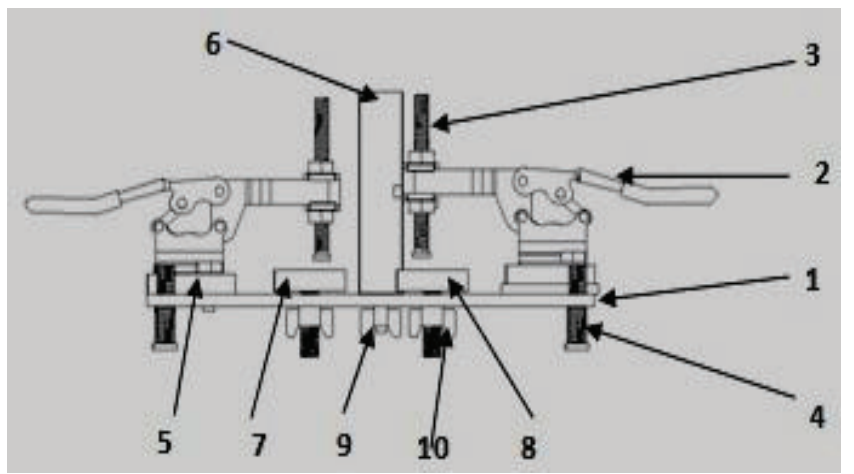

Figure 9. Welding Fixture Assembly (indicating all parts)

\section{A. Fixture Design: Butt Joint}

To obtain butt joint, rest pads are in contact with the base plate. Weld plates are butt together and gripped against toggle clamps on rest pads as shown in Figure 10. Mounting and removal of weld parts are simple as well as plates of variable thicknesses can also be welded in this setup.

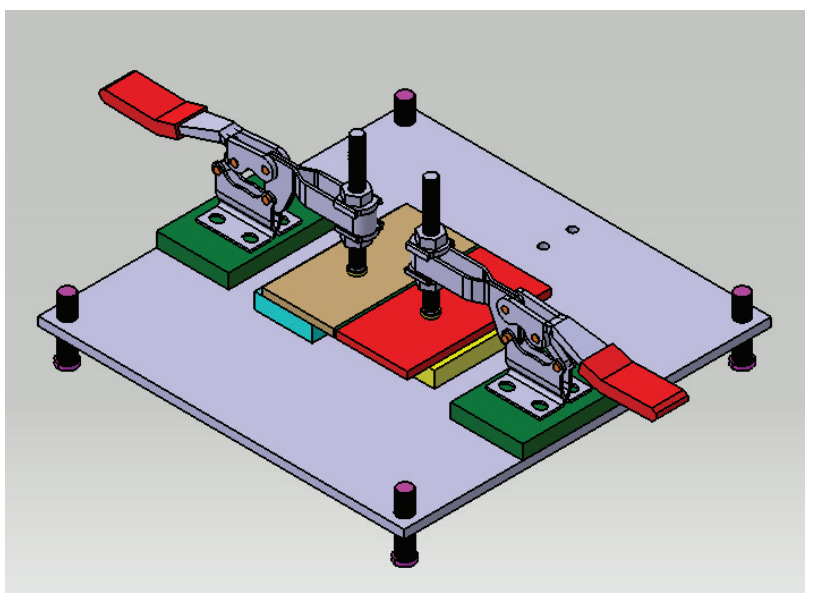

Figure 10. Designed Welding Fixture: Butt Joint

\section{B. Fixture Design: LapJoint}

To obtain designed lap joint, one rest pad is to be lifted to the height of weld plate. Then the weld plates can overlap upto required length and can be gripped by toggle clamps as shown in Figure 11. For fillet weld on the other side, plates have to be unmounted. After inverting them again, they can be gripped under toggle clamp to perform fillet weld.

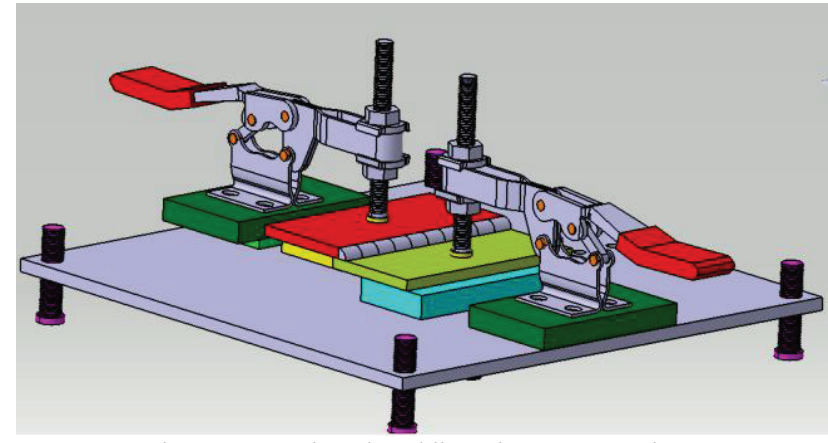

Figure 11. Designed Welding Fixture: Lap Joint

\section{Fixture Design: T-Joint}

To obtain T- joint, designed bracket is to be attached to the base plate. Horizontal plate may rest over rest pads but the vertical plate is to be rested in bracket by properly aligning in bracket. The horizontal plate can be gripped against clamp and the vertical plate will be held with fasteners in the bracket, as shown in Figure12.

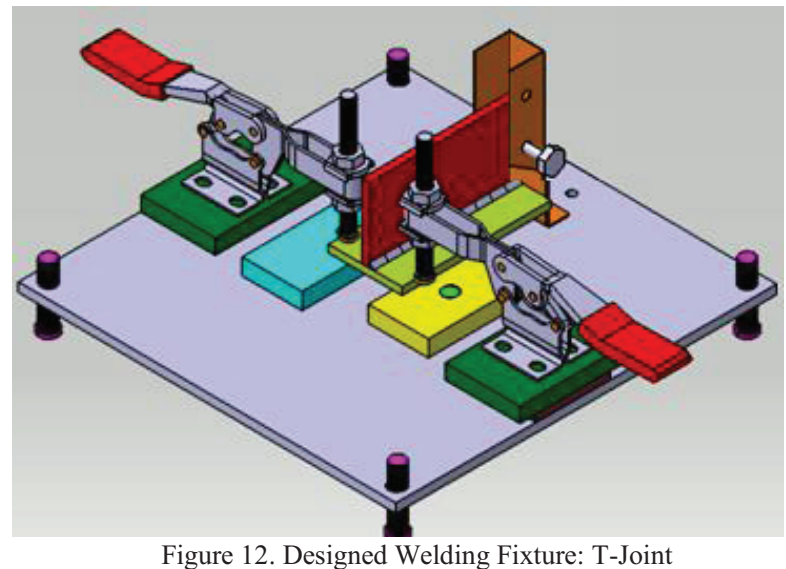

\section{ANALYSIS}

Static load and thermal analysis are performed on the designed fixture in order to ensure feasibility of designed fixture. ANSYS 16.0 is utilized for this purpose.

\section{A. Static Load Analysis}

Static load analysis helps us to know deformation pattern of designed fixture under applied static loads. This analysis may further help us to estimate size and weight of workpiece to be accommodated over the fixture. 
Static load analysis is performed on butt joint arrangement of the fixture. The similar loading situation and obtained result can be approximated for lap and T-joint.

Loading condition includes weight of plate and clamping force. Loading condition is indicated in Figure 13.

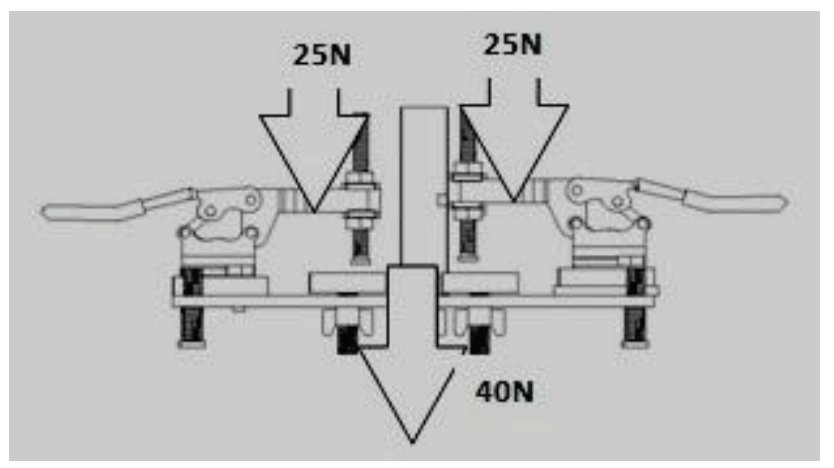

Figure 13. Loading Condition for Static Load Analysis

Based on loading condition Von Mises Stress analysis and deformation analysis is done for butt joint. Figure 14 and Figure 15 indicates results obtained for Von Mises stress and deformation analysis respectively. Observations are listed in Table IV.

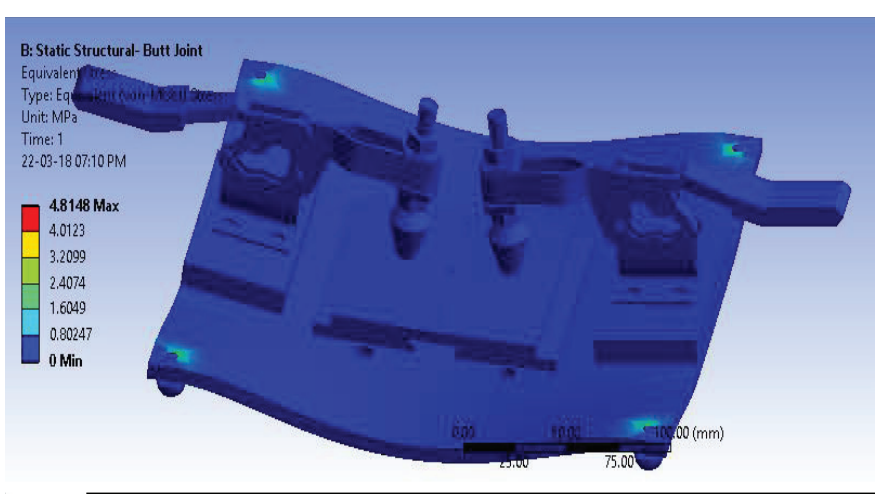

Figure 14. Von Mises Stress During Butt Joint

TABLE IV.

ANALYTICAL OBSERVATIONS

STATIC LOAD ANALYSIS BUTT JOINT

\begin{tabular}{|l|l|}
\hline Minimum Stress & $0 \mathrm{MPa}$ \\
\hline Maximum stress & $4.8148 \mathrm{MPa}$ \\
\hline Minimum Stress on & Support \\
\hline Maximum stress on & Clamp \\
\hline Minimum Deformation & $0 \mathrm{~mm}$ \\
\hline Maximum Deformation & $0.0028164 \mathrm{~mm}$ \\
\hline Minimum Deformation on & Support \\
\hline Maximum Deformation on & Clamp \\
\hline
\end{tabular}

\section{B. Thermal Analysis}

Thermal analysis is necessary here to know the effect of heat liberated by the process of welding on the fixture setup.

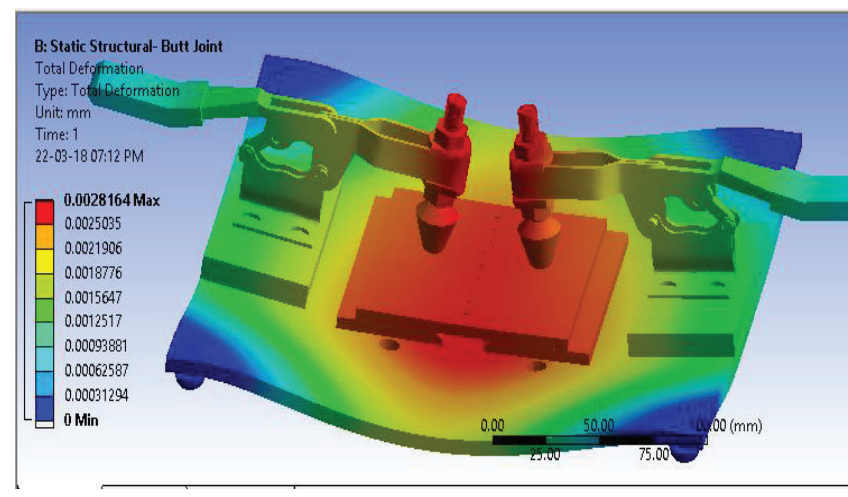

Figure 15. Total Deformation During Butt Joint

Usually in SMAW width of arc is wide. A wide arc zone contributes to wide heat affected zone and this widely dispersed amount of heat may harm other fixture parts in long production run.

Transient thermal analysis is done using ANSYS 16.0 to estimate temperature distribution on fixture surface. Thermal analysis on welding fixture for butt joint arrangement is shown in Figure 16. Figure 17 and Figure 18 are indicating thermal analysis results in lap and T-joint condition. Observations of the thermal analysis are indicated in Table V.

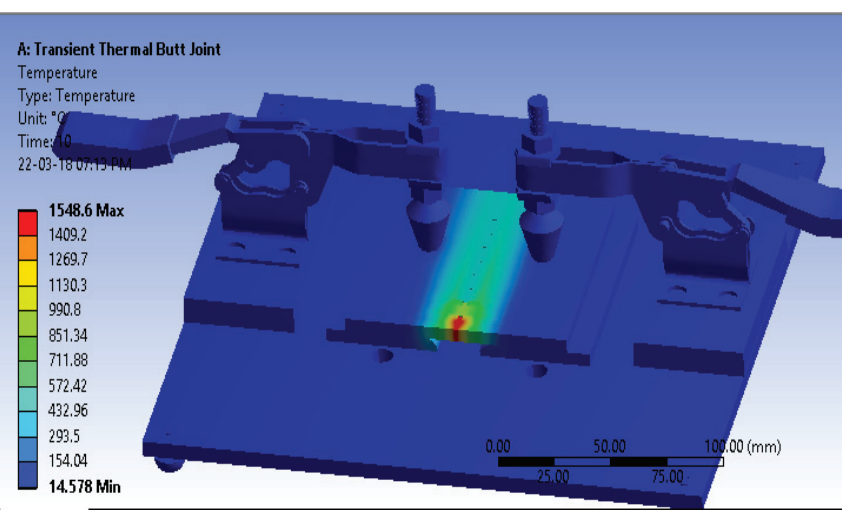

Figure 16. Thermal Analysis During Butt Joint

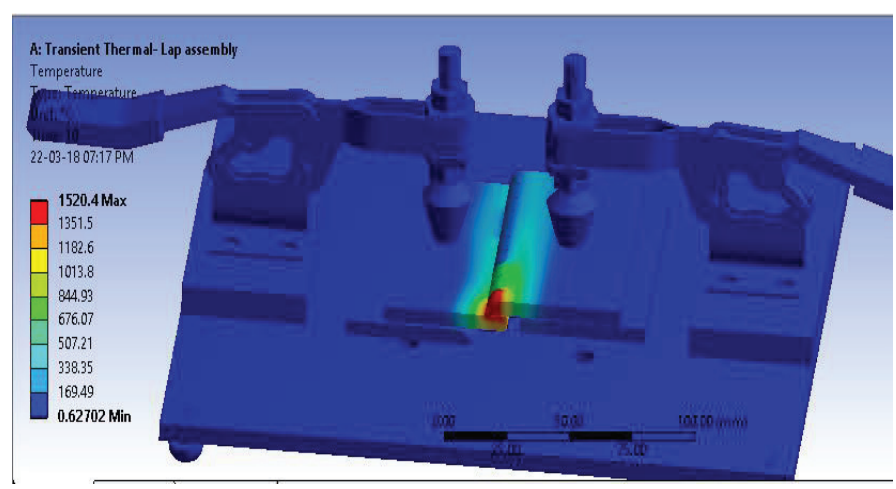

Figure 17. Thermal Analysis During Lap Joint 


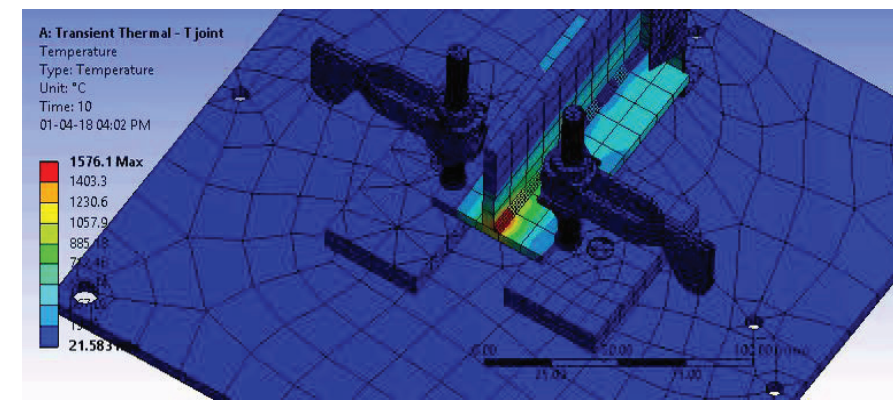

Figure 18. Thermal Analysis During Lap Joint

TABLE V.

ANALYTICAL OBSERVATIONS

THERMAL ANALYSIS ON JOINTS

\begin{tabular}{|l|l|l|l|}
\hline Parameters / joints & Butt Joint & Lap Joint & T-joint \\
\hline Min.Temperature & $14.578^{\circ} \mathrm{C}$ & $21.191^{\circ} \mathrm{C}$ & $21.584^{\circ} \mathrm{C}$ \\
\hline Max.Temperature & $1548.6^{\circ} \mathrm{C}$ & $1519.2^{\circ} \mathrm{C}$ & $1576.1^{\circ} \mathrm{C}$ \\
\hline Min.Temperature on & Weld Plates & Weld Plates & Weld Plates \\
\hline Max.Temperature on & Weld Plates & Weld Plates & Weld Plates \\
\hline
\end{tabular}

Obtained results clearly indicate that there is no distortion on weld plate, thus the designed fixture is able to overcome the problem of distortion in the welded plates.

Similarly thermal analysis in case of various welded joints shows that the parts of fixture are not much affected by heat liberated in the process of welding

\section{CONCLUSIONS}

In a welding process like shielded metal arc welding (SMAW), harmful radiations, intense heat of welding, smoke etc. increases difficulty for a welder. While protecting himself from these difficulties holding heavy electrode holder and aligning metallic workpiece becomes additional task for him.

Based on obtained analysis results, it can be stated that the designed fixture is a feasible design based on considerations. Such fixtures are easy to manufacture at less cost and quite convenient to use. Thus they can be suitably implemented to ease the efforts of the welder. As well as the fixture can serve as a part of academic and experimental set up for analysis of different methods of welding over various metals. The research work in this paper shows welded joints on flat plates but the same fixture can be utilized for obtaining joints on similar profiled plates for industrial applications.

The use of fixtures discussed in this report is limited for joining of flat plates. Additional attachments can be designed so that the same fixture can be used for joining circular piece parts also. Estimation of temperature rise in fixture after a number of welding can be scope for further research.

As, human factor is the main reason of faults in welding as well as in other manufacturing processes, automation is observed as single hand solution. Despite the decrease of human factor, full automation is not always a feasible solution [8]. Initial cost of an automated system and lot size of production are main factors to consider before atomization of any process.

Usually each welding fixture is designed for fabrication of specific part requirement which decreases there versatility. At the same time an innovative approach of fixture design makes it versatile in use.

\section{REFERENCES}

[1] Roy A. Lindberg, Processes and Materials of Manufacturing, $4^{\text {th }}$ Edition, pp 623-624, 2011

[2] Lien TK, Lind M., Instrumented fixtures for on-line correction of welding paths. 41st CIRP conference on manufacturing systems, pp. 435-438, 2008.

[3] Sikstrom F., Ericsson M., Christiansson A.K., Tools for simulation based fixture design to reduce deformation in advanced fusion welding. $1^{\text {st }}$ International conference on intelligent robotics and applications. Part II, pp. 398-407, 2008

[4] P H Joshi, Jigs and Fixtures, $3^{\text {rd }}$ Edition, pp 169-170, 1988

[5] Kalpakjian S. and Steven R. Schmid, Manufacturing Engineering and Technology. Pearsion Education, $4^{\text {th }}$ Edition, pp. 166 and 799-800, 1995

[6] M. Vural, H. F. Muzafferoglu, V. C. Tapici, The Effect of Welding Fixtures on Welding Distortions, journal of achievements in materials and manufacturing engineering. Issue 1-2, volume- 20, pp 511-514, 2007

[7] Martin L. Culpepper, Design of a hybrid positioned fixture for six axis nanopositioning and precision fixturing, pp 65-80, 2005

[8] M.A. Wahab, M.J. Painter, M.H. Devis, The prediction of the temperature distribution and weld pool geometry in the gas metal arc welding process, Journal of Material Processing Technology, Vol. 77, Issues 1-3, pp 233-239, 1998 